\title{
Eddy formation around South West Mascarene Plateau (Indian Ocean) as evidenced by satellite 'global ocean colour' data
}

\author{
M. Rezah Badal', S.D.D.V Rughooputh², Lars Rydberg33, lan S. Robinson ${ }^{4}$ \\ and Charitha Pattiaratchi ${ }^{5}$ \\ ${ }^{1}$ Mauritius Oceanography Institute, ${ }^{2}$ University of Mauritius, Reduit, Mauritius, ${ }^{3}$ Department of \\ Earth Sciences, University of Gothenburg, PO Box 460 SE-405 30 Göteborg, Sweden, ${ }^{4}$ National \\ Oceanography Centre, University of Southampton Waterfront Campus, European Way, Southampton \\ SO14 3ZH, England, ${ }^{5}$ Group School of Environmental Systems Engineering Mailstop MO15 \\ University of Western Australia 35, Stirling Highway Crawley, WA 6009 Australia.
}

Keywords: Indian Ocean, Mascarene Plateau, Ocean color, Altimeter, Sea Surface Temperature.

\begin{abstract}
The identification of an eddy formation, south-west of the Mascarene Plateau, is demonstrated in global ocean colour data derived from the Aqua-MODIS satellite. In spite of a weak signature, construction of a monthly average plot using scaling techniques for the year 2004 allows the observation of an eddy structure for the month of June from the Aqua-MODIS data. The presence of an eddy is further substantiated by the application of altimetric data. The geostrophic velocities derived from altimeter data revealed that the current was moving in a clockwise direction that propagated in an east-west trend with higher geostrophic velocities $(30-40 \mathrm{~cm} / \mathrm{s})$ in the southern limb. This eddy can be characterised as a meso-scale and intermittent oceanic feature with a size of around $225 \mathrm{~km}$ diameter that traveled to a distance of $100-150 \mathrm{~km}$ in a fortnight, after which it started to decay.
\end{abstract}

\section{INTRODUCTION}

The Indian Ocean and more precisely the South Indian Ocean (SIO) is still looked upon as a poorly studied ocean. In contrast much is known about the monsoonal influence in the Northern Indian Ocean and about its effect on the oceanography and climate of the region. On the other hand, the physical oceanography of the SIO is somehow less understood (New et al., 2005). This is attributed to relatively few research surveys and consequently less data availability. It is subsequent to the RRS Charles Darwin hydrographic survey in 2002, that
New and others have attempted to develop an understanding of the large-scale flow patterns and water masses which are present and which may affect a section of the SIO, namely the Mascarene Plateau. However, knowledge on the behaviour of the flow is relative sparse and little is known on its seasonal relationship with other geophysical parameters like temperature and chlorophyll concentrations except for some seasonal signatures of enhanced concentrations peaking around May and August (Badal, 2002). Eddy formation, which is believed to be important in biological processes, has only been indicated in this part of this ocean. 


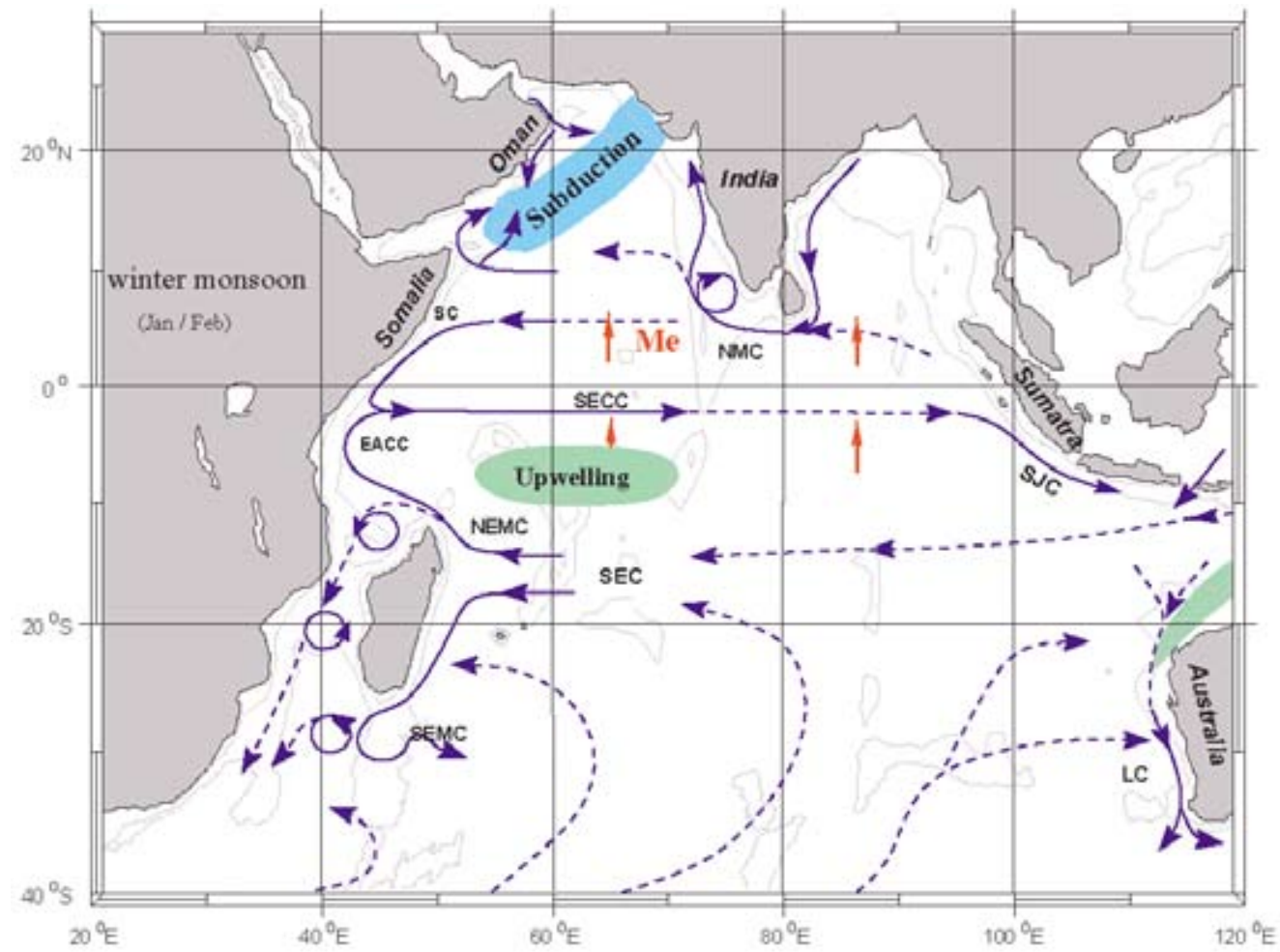

Fig. 1. A schematic representation of Equatorial upwelling in the Indian Ocean (reproduced with permission from Schott et al., 2002)

Few studies have been conducted in the region of the Mascarene Plateau to describe the dynamics of the flows across it (Devassy and Goes, 1991; Schott \& McCreary, 2001). An early description, of the flow dynamic and thermohaline structure of the Mascarene region described a divergence zone that could be operating on the western part of the plateau (Ragoonaden et al., 1987). In their study they used data that were collected from the International Indian Ocean Expedition in the late 1950s and 1960s. Schott and McCreary (2001) remarked the occurrence of Ekman divergence during the NE monsoon (Fig. 1) that would result in occasional upwelling at the northern edge of the South Equatorial Current (SEC).

Schott and McCreary also confirmed the bifurcation into two major currents as the SEC impinges on the Mascarene Plateau.
This phenomenon has been observed from Acoustic Doppler Current Profiler (ADCP) measurements undertaken through the hydrographic survey by RRS Charles Darwin in June-July 2002. They described these current systems as a "northern and southern core', with the northern core passing through the Plateau in between Saya de Malha and Nazareth Banks, and the southern core passing between south of Carcados Carajos Banks but north of Mauritius Island (Fig. 2). In addition they indicated, as Ragoonaden et al. (1987), of the likely presence of an eddy or meander near $16^{\circ} \mathrm{S}, 57^{\circ} \mathrm{E}$ on the leeside of the plateau.

In this paper ocean colour satellite data is used to track the presence of an eddy around the above location. The attempt to substantiate the presence of an eddy is made through the application of altimetry data, namely Absolute Dynamic Topography (ADT). 


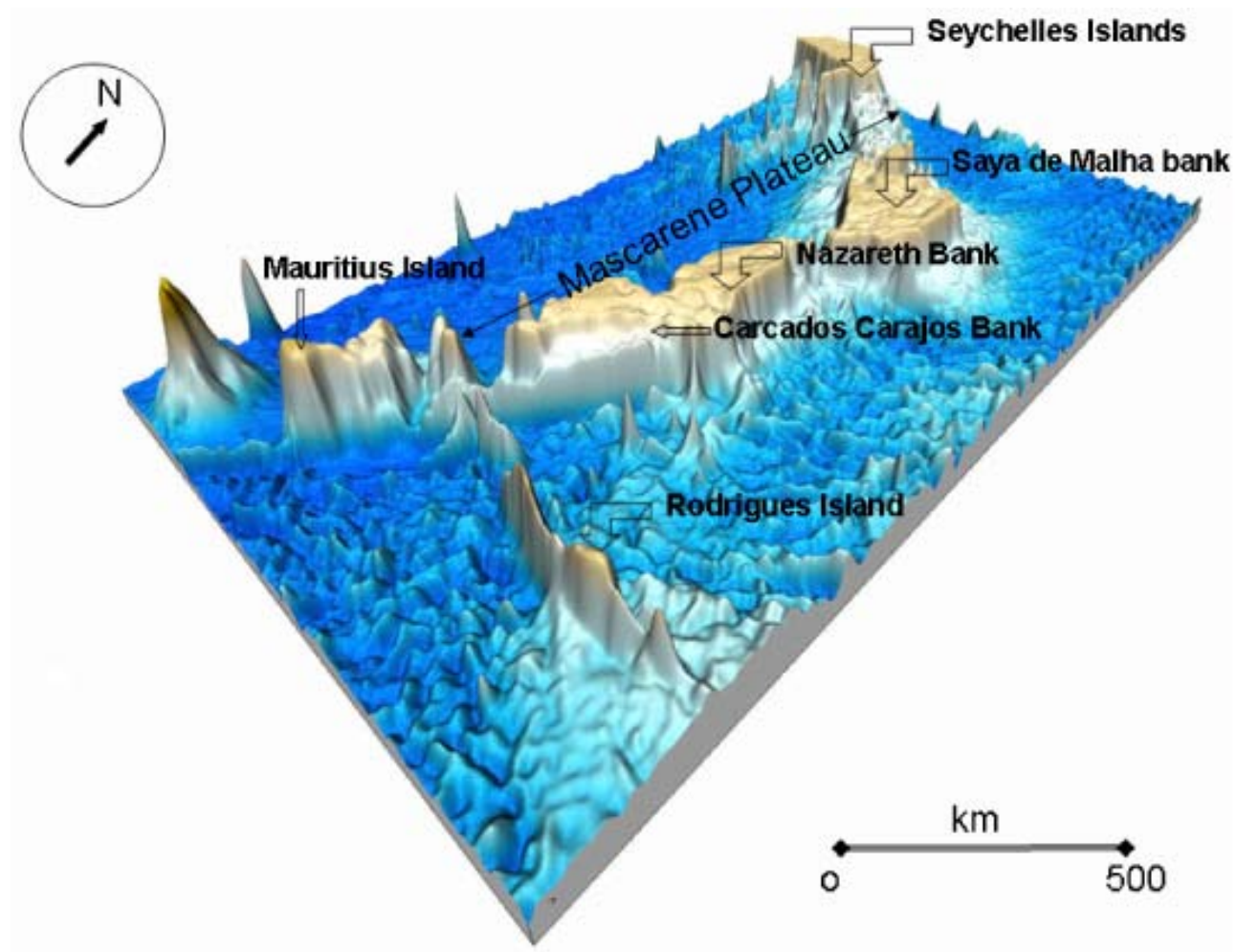

Fig. 2. Sea floor topography from Altimetry and echo sounding, (data source: ETOPO1 and National Geophysical Data Centre)

\section{DATA AND METHODS}

The main data are obtained from NASA ocean color and the Archiving, Validation and Interpretation of Satellite Oceanographic (AVISO) internet websites (http://www.aviso. oceanobs.com/en/data/product-information/ duacs/index.html). Chlorophyll concentrations (Chl-a) measured onboard the Aqua-Modis satellite represents the data on ocean colour while the derived ADT and geostrophic velocities are the altimetric data. Both datasets were studied for the period January 2003 to December 2005.

Chl-a concentrations and ADT were extracted from the global dataset in order to locate the formation of eddies region bounded by the latitude $5^{\circ} \mathrm{S}$ to $25^{\circ} \mathrm{S}$ and longitude $45^{\circ} \mathrm{E}$ and $65^{\circ} \mathrm{E}$ (Fig. 3). The chlorophyll raw data is obtained in the form of digital numbers (DN values) and a linear algorithm (http:oceancolor.gsfc.nasa.gov/DOCS) has been applied to determine the geophysical parameters. These data were statistically re-sampled into monthly averages, which correspond to a 4 X $4 \mathrm{~km}$ spatial resolution and were plotted using 'Matlab' scripts. Selected bathymetric contours and coastline vector data, extracted from General Bathymetric Chart of the Oceans (GEBCO) 2003, were superimposed on the charts. Such technique allows the production of animated plots (not shown here), from which the direction of the moving fronts can be determined. Plots of ADT and geostrophic velocities at the resolution of $1 / 3 \times 1 / 3$ degree were also constructed using the same techniques. 


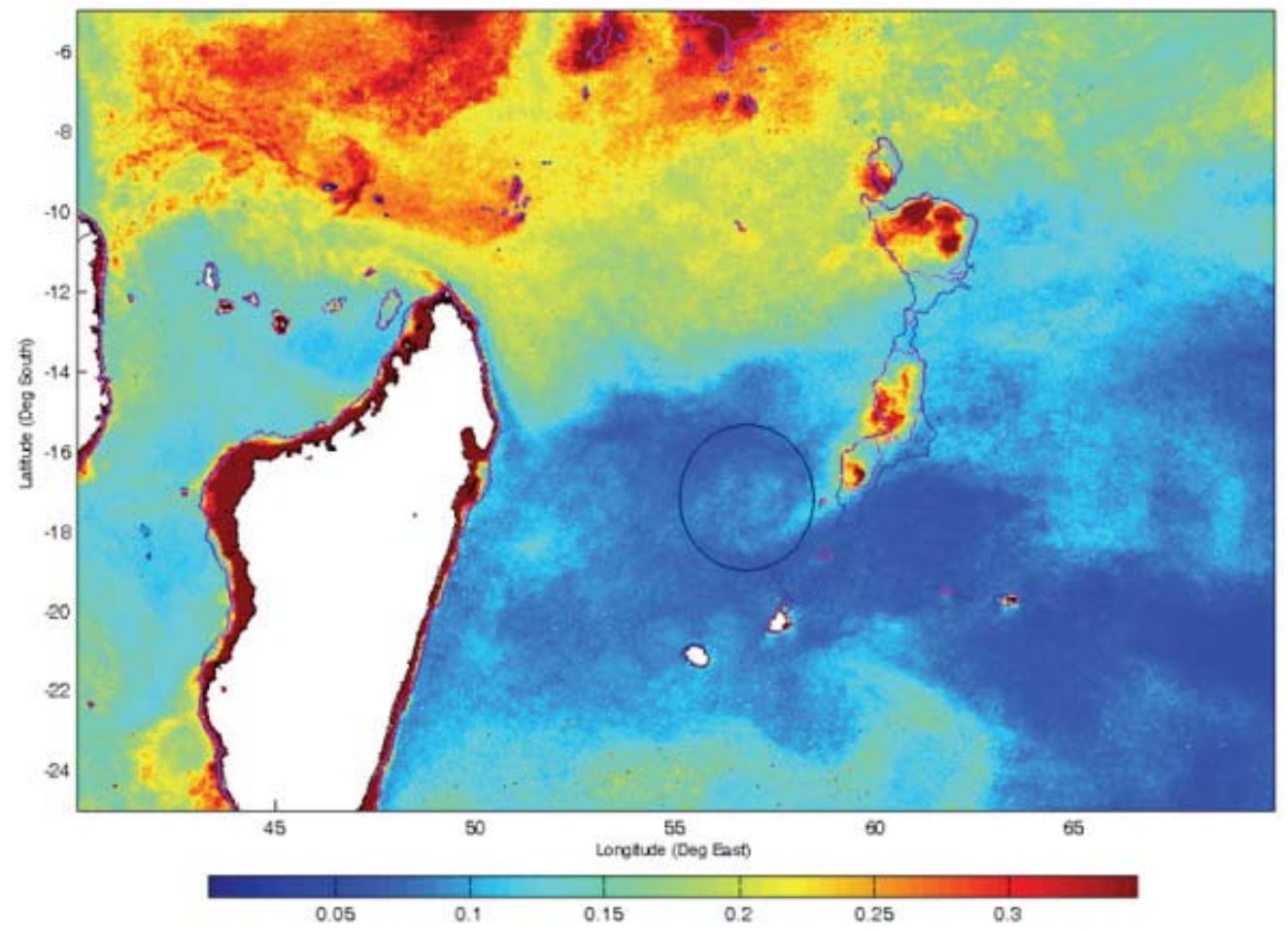

Fig. 3. Chlorophyll distribution (mg/m³), SW Indian Ocean, June 2004 (data source: SeaWIFS)

\section{RESULTS}

The average monthly Chl-a concentrations were visually examined for the presence of eddy in the region of the Mascarene Plateau for the period between January 2003 and December 2005. In general no prominent oceanic phenomenon that carried a chlorophyll signature could be tracked, except for 2004. The month of June 2004, in particular, revealed to be far more productive than the previous months of the same year. This would indicate the effect of the onset of southern winter's (May-September), in which primary production is expected to start.

This observation is actually the opposite of what occurs in the temperate region where summer usually triggers the period of higher primary production. Badal, 2002, demonstrated this opposed seasonality pattern on primary production based on a correlation between Chl-a (primary production), SST and sea surface height. The seasonality of the wind was suspected to be responsible for the enhanced 'Chl-a' during southern winter.

A close-up on June 2004 Chl-a distribution, revealed effectively the presence an eddy structure (Fig. 3) at the position $16^{\circ} \mathrm{S}$ and $57^{\circ} \mathrm{E}$. The diameter of about $225 \mathrm{~km}$ of the eddy depicts its meso-scale nature

The study was then directed to find out whether the eddy formation had any signature on the sea surface topography. Charts of corresponding ADT and geostrophic velocities were constructed for June 2004. In the analysis of these altimetric parameters a merged dataset from AVISO, which include data collected from a number of altimeters, was used. Data were available for nearly every four days for June 2004 (Fig. 4). Although the visual analysis of the whole study area appears complicated, the main current patterns are discernable. The two core currents derived from the SEC (New et al., 2005) as it impinges on the Mascarene 

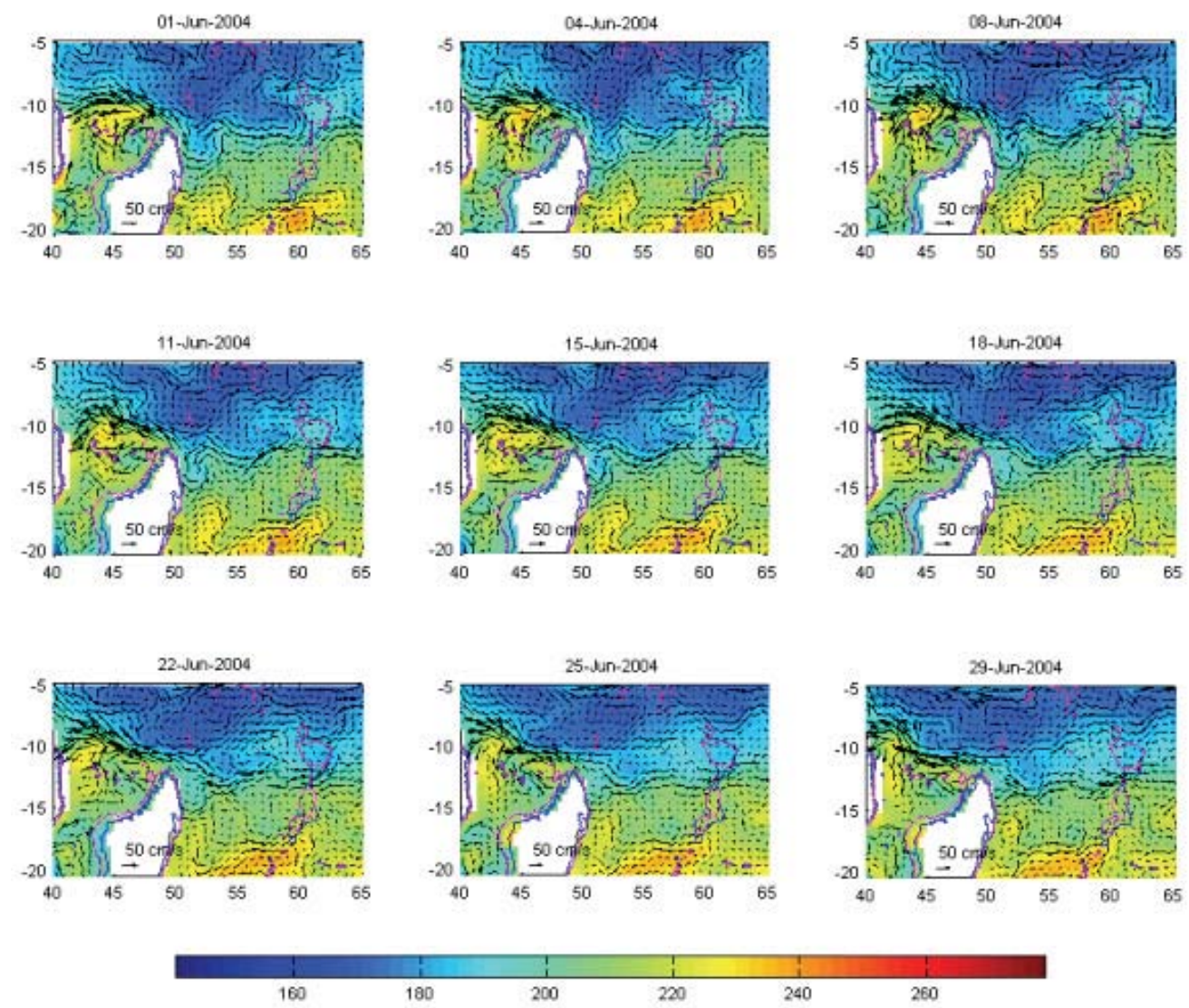

Fig. 4. Absolute dynamic topography (cm) and geostrophic velocities $(\mathrm{cm} / \mathrm{s}), 1$ - 29 June 2004, (data source: AVISO)

plateau are observable. The northern sector appears to have a lower topography than the southern part where the dynamics are much higher (Fig. 4), in that a greater number of eddies are observed.

We then tried to locate any apparent signature on the topography and current in the region where the eddy was identified. As expected, although the charts produced were on a higher scale ( $1 / 3 \times 1 / 3$ degree), a clockwise rotation could be spotted in the tracking zone as from mid of June 2004. A small depression in the sea surface topography is also observed (Fig. 5). We then played each frame depicted in figure 5 as a movie, where the east-west propagation of the eddy could be observed

\section{DISCUSSION}

The result above showed an eddy formation south-west of the Mascarene Plateau (Fig. 3 and 5). The fact that it bears a chlorophyll signature demonstrates the effect of such eddies on the primary production in the region.

The presence of an eddy is further substantiated by the application of altimetric data. It is demonstrated, from the results of the ADT and geostrophic charts, that there was effectively an eddy formation in the south-west of the Mascarene Plateau (Fig. 5). The geostrophic velocities clearly depict the clockwise rotation of the eddy. 

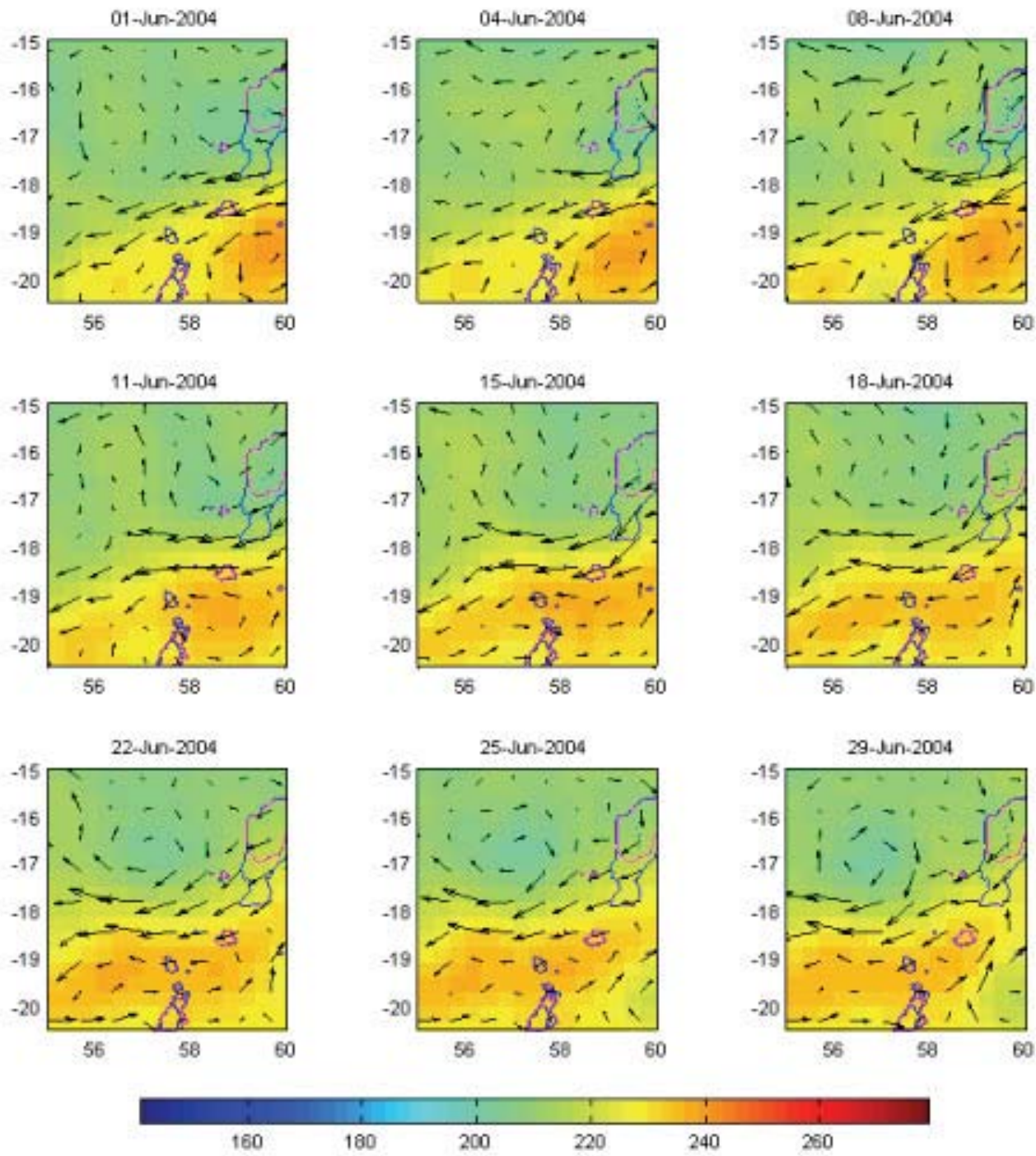

Fig. 5. Absolute dynamic topography (cm) and geostrophic velocities, 1-29 June 2004, South West of the Mascarene Plateau, (data source; AVISO)

As the eddy was observed during a limited time in June 2004, there is reason to believe that such formation has an intermittent character. It is likely that this eddy could be associated with the local wind regime and the seabed topography.

The eddy formation was further investigated as to whether it will create upwelling in this region of the plateau. Sea surface temperatures data were analysed for this particular region to locate the presence of cold water around the centre of the eddy. However, the result of the analysis does not reveal any convincing presence of a cold ring, except for a few slightly colder spots. Therefore this eddy does not seem to be associated with any upwelling. 


\section{CONCLUSION}

This study has explored the advantages to be gained from interpreting and analyzing ocean colour images in combination with corresponding image data obtained from different type of sensors, namely current, ADT and SST. The practice has come to be referred to, in ocean remote sensing, as the use of synergy (Ufernamm et al., 2001, Robinson, 2004). This study has in effect been able to confirm the presence of an eddy through the use of both ocean colour and altimetry data. This intermittent meso-scale oceanic eddy is apparently linked to the bathymetric features in the region of the Mascarene Plateau. In the absence of a cold core ring, it seems likely that the enhanced chlorophyll concentrations could be linked to phytoplankton, which are concentrated on the banks of the plateau and that are ultimately dragged along the eddy path, acting as a tracer.

Acknowledgements-The altimeter products were produced by Ssalto/Duacs and distributed by Aviso, with support form Cnes.

The SST and ocean colour data are acknowledged to Feldman, G. C., C. R. McClain, Ocean Color Web, Aqua-MODIS Reprocessing level 3, NASA Goddard Space Flight Center. Eds. Kuring, N., Bailey, S. W.25 May 2006. http://oceancolor.gsfc.nasa.gov/

The Mauritius Oceanography Institute, the Mauritius Research Council and the University of Mauritius are acknowledged for their supports.

\section{REFERENCES}

Badal, M. R. (2002). Enhanced Primary Production on the Mascarene Plateau caused by a Mini Monsoon. Proc. SPIE, Ocean Remote Sensing \& Application vol. 4892: 305-311.

Devassy, V.P., and Goes, J.I. (1991). Phytoplankton assemblages and Pigments in the exclusive economic zone of Mauritius (Indian Ocean). Indian Journal of Marine Science, Vol. 20: 163-168.

New A. L, Stansfield K., Smythe-Wright D., Smeed D.A., Evans A.J. and Alderson S.G. (2005). Physical and biochemical aspects of the flow across the Mascarene Plateau in the Indian Ocean. Phil. Trans.R. Soc. 363: 151-168.

Ragoonaden, S., Ramesh Babu V., Sastry J.S. (1987). Physico-chemical characteristics and circulation of waters in the MauritiusSeychelles Ridge zone, Southwest Indian Ocean. Indian Journal of Marine Sciences, Vol. 16: 184-191.

Robinson I. S. (2004). Measuring the oceans from space. Springer-Praxis, Chichester, UK , 669 pp.

Schott F.A., Dengler M., Schenefeldt R. (2002). The shallow overturning circulation of the Indian Ocean. Progress in Oceanography, 53: $57-103$.

Schott F. A. and McCreary J.P. (2001). The monsoon circulation of the Indian Ocean. Progress in Oceanography, 51: 1-123.

Ufermann, S., Robinson, I. S. and da Silva, J.C. B. (2001). Synergy between synthethic aperture radar signatures of the Gulf stream front. $J$. Geophys. Res., 104(c11): 25697-25706. 